\title{
Single track scanning experiment on the hypereutectic aluminium alloy $\mathrm{Al}-8 \% \mathrm{Zn}-7 \% \mathrm{Ni}-3 \% \mathrm{Mg}$
}

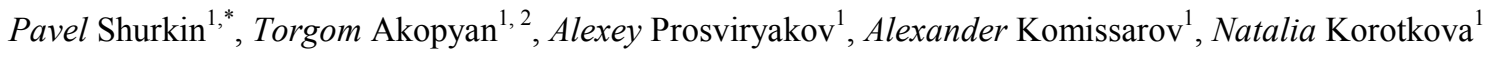 \\ ${ }^{1}$ National University of Science and Technology "MISIS", 119049, Leninskii pr., 4, Moscow, Russia \\ ${ }^{2}$ Baikov Institute of Metallurgy and Materials Science, 119991, Leninskii pr., 49, Moscow, Russia
}

\begin{abstract}
Solidification path, hot tearing susceptibility and processability by L-PBF of the hypereutectic aluminium alloy $\mathrm{Al}-8 \% \mathrm{Zn}-7 \% \mathrm{Ni}-3 \% \mathrm{Mg}$ were investigated. It was shown that the alloy has an advantageous hot tearing resistance due to formation of an adequate amount of the [( $\left.\mathrm{Al})+\mathrm{Al}_{3} \mathrm{Ni}\right]$ eutectic and a reduced effective solidification range. In that sense, it may be valid for L-PBF. To prepare a feedstock for L-PBF, we produced chips which were subsequently grinded by high-energy ball milling into a $100 \mathrm{~m}$ fine powder batch. The powder contained irregular shape particles that may have led to failure in fabrication of regular single tracks at a laser power of 170-250 W and scanning speed of 200-350 mm/s. Whilst from on-top view all the tracks had defects like balling and irregularity, their cross-sections also revealed a high degree of penetration into 5052 alloy substrate. Most structures showed a level of mixing of $5 / 1$ between the substrate and the experimental alloy. The most successful track obtained at $250 \mathrm{~W}$ and $250 \mathrm{~mm} / \mathrm{s}$ showed an inhomogeneity in distribution of the alloy-rich regions. Meanwhile, no defects and no primary $\mathrm{Al}_{3} \mathrm{Ni}$ phase were observed. The present study serves as an initial one for further research which may be focused on producing of a finer powder, assessment of different layer thicknesses and fabrication of bulk specimens.
\end{abstract}

\section{Introduction}

Metal-based laser additive manufacturing is a wide field of material science requiring for careful selection of composition that is considered to be the most critical for synthesis of minimal-defect products. Among a great variety of methods the laser powder bed fusion (hereafter referred to as L-PBF) is an advance process based on laser beam travel along the metallic powder batch presenting an opportunity to produce complex functional parts for various purposes [1-3].

Among numerous compositions for L-PBF investigated through years, the aluminium based materials present some complications. In comparison to steels, titanium or magnesium, aluminium is a good heat conductor, but its laser absorption is lower. In this case a higher laser power has to be applied [4]. Nevertheless they are believed to be the most attractive for light-weight application due to their low density $\left(\sim 2.7 \mathrm{~g} / \mathrm{cm}^{3}\right)$, easy conventional manufacturing and possibility of secondary stock usage [5].

It is certainly known that the most studied aluminium alloys for L-PBF are Al-Si alloys, perfect for producing cast products as well [5, 6-9]. A good fusion ability of powder particles is caused by specific solidification path which contains eutectic reaction $[\mathrm{L} \rightarrow(\mathrm{Al})+(\mathrm{Si})]$ at $577{ }^{\circ} \mathrm{C}$. Non-eutectic alloys (Al-Zn-Mg, $\mathrm{Al}-\mathrm{Cu}$, etc.) are not appropriate for L-PBF due to wide solidification range [4]. Attempts to produce L-PBF parts from the high-strength Al-Zn-Mg alloys leaded to extensive formation of hot cracks [9]. Therefore several works are devoted to preparing silicon-added mixture based on Al$\mathrm{Zn}-\mathrm{Mg}$ matrix which provides enough appropriate cracks resistance $[10,11]$.

However, we suppose that there are some risks related to loss of strength may occur due to possible $\mathrm{Mg}_{2} \mathrm{Si}$ phase formation. There are some eutectic forming elements which are believes to be promising for replacing silicon $[12,13]$. Our attitude toward the issue of L-PBF of Al$\mathrm{Zn}-\mathrm{Mg}$ alloys is slightly similar, but we decided to use nickel instead of silicon. Al-Zn-Mg-Ni alloys based on the $\left[(\mathrm{Al})+\mathrm{Al}_{3} \mathrm{Ni}\right]$ are proved to have excellent fluidity and hot tearing resistance $[5,14]$. Moreover, since there is no interaction between pair $\mathrm{Zn} / \mathrm{Mg}$ and $\mathrm{Ni}$ it is possible to fabricate a natural particulate-reinforced composite material by an increase in $\mathrm{Ni}$ content up to hypereutectic concentration. In favour to this approach, Al-20\% Si hypereutectic alloy was fabricated in [15] and after a pseudo-eutectic cellular microstructure was observed as a result. This is due to high cooling rates (more than $10^{3}-10^{7} \mathrm{~K} / \mathrm{s}$ [16]) provided by rapid laser spot movement.

In this initial work we do not consider the cooper addition because of its harmful effect on the fluidity and hot tearing resistance [17]. We chose the strongest Al$\mathrm{Zn}-\mathrm{Mg}$ matrix related to commercial alloys (e.g. 7001, 7090,7055 , etc.) [18]. Research on rapid solidification of the Al-Ni hypereutectic alloys reported that the

Corresponding author: pa.shurkin@gmail.com 
pseudo-eutectic ultrafine structure can be achieved at 7$8 \% \mathrm{Ni}[19,20]$. Thus the main experimental alloy in the present work is a $\mathrm{Al}-8 \% \mathrm{Zn}-7 \% \mathrm{Ni}-3 \% \mathrm{Mg}$. Starting from the first principles the experiment was conducted through powder fabrication by high-energy ball milling (hereafter referred to as HEBM). This approach is an advantageous due to lack of necessity to consider expensive gas atomization. Some successful experiences on L-PBF of Al-based and Fe-based alternative powder feedstock are observed in $[21,22]$. The core of the present work is to investigate the molten pool behaviour during L-PBF and the microstructure evolution in order to substantiate the prospects of the alloy and tailor a route for further works.

\section{Materials and methods}

The work was focused on producing of samples and its characterization. Firstly, we conducted a hot tearing test of three alloys Al-8\% $\mathrm{Zn}-3 \% \mathrm{Mg}$, Al-8\%Zn-4\%Ni-3\%Mg and $\mathrm{Al}-8 \% \mathrm{Zn}-7 \% \mathrm{Ni}-3 \% \mathrm{Mg}$ in order to substantiate the choice of the alloy composition. Secondly, the analysis of the non-equilibrium solidification was carried out by Scheil-Gulliver simulation in Thermo-Calc software (TTAL5 Al-alloys database) [23] for prediction of the microstructure. Finally, the powder was produced, which was used as a feedstock in a single track experiment.

\subsection{Preparation of samples}

The alloys were produced via melting of pure aluminium $(99.9 \% \mathrm{Al})$, zinc $(99.9 \% \mathrm{Zn})$, magnesium $(99.9 \% \mathrm{Mg})$ and $\mathrm{Al}-20 \% \mathrm{Ni}$ master alloy in an electrical laboratory furnace Nabertherm $\mathrm{K} 1 / 13$. Hot tearing test was performed via pouring the molten metal into a backbone mould with variation of diameter from $16 \mathrm{~mm}$ to $10 \mathrm{~mm}$. The experimental alloy $\mathrm{Al}-8 \% \mathrm{Zn}-7 \% \mathrm{Ni}-3 \% \mathrm{Mg}$ was also poured into a graphite cylindrical mould of $40 \times 280 \mathrm{~mm}$ in size. The raw material for the single track experiment was irregular shaped powder produced from the alloy chips (fig. 1). The $150 \mathrm{~g}$ batch was milled into powder in air using a 4-reel Retsch PM 400 planetary ball mill at $300 \mathrm{rpm}$. The weight ratio between the stainless-steel balls and the experimental alloy chips was 10:1. After 10 min of dry grinding, the powder was sieved so to achieve a less than $100 \mu \mathrm{m}$ size, following which the remaining coarse fraction was milled again. The total milling time was $30 \mathrm{~min}$.

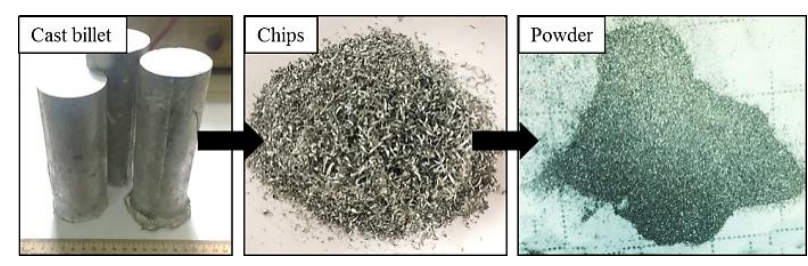

Fig. 1. Powder fabrication route used in this study

The powder batch put onto $5052(\sim \mathrm{Al}-5 \% \mathrm{Mg})$ alloy substrate was loaded into SLM $280 \mathrm{HL}$ machine. The laser was travelled just one time along the lines of 120 $\mathrm{mm}$ length. The powder was melted at a laser power of
$170,200,250 \mathrm{~W}$ and a scanning speed of 200, 250, 300, $350 \mathrm{~mm} / \mathrm{s}$ (12 tracks in total). The thickness of layer was about $150 \mu \mathrm{m}$.

\subsection{Characterization}

The microstructure, width and height of tracks was examined by optical microscopy (OM, Axio Observer MAT) and scanning electron microscopy (SEM, TESCAN VEGA3) equipped with an electron microprobe analysis system (EMPA, Oxford Instruments). The metallographic samples were ground using a $\mathrm{SiC}$ abrasive paper and polished with a $1 \mu \mathrm{m}$ diamond suspension. A $1 \%$ hydrogen fluoride (HF) water solution was used for etching. The particle-size distribution of the powder was studied using an Analysette 22 laser particle analyser. The parameters $\mathrm{D}_{10}, \mathrm{D}_{50}, \mathrm{D}_{90}$, which are the cumulative particle diameters for $10 \%, 50 \%$, and $90 \%$ of the entire powder volume, were determined. The SPAN parameter was calculated using the equation [24]:

$$
S P A N=\frac{D_{90}-D_{10}}{D_{50}}
$$

\section{Results and discussion}

\subsection{Hot tearing susceptibility}

Hot tearing susceptibility mainly depends on solidification path, which may be described by thermodynamic calculation. A comprehensive description of phase equilibria in Al-Zn-Mg-Ni system is described in our recent paper [25]. It is observed that a $\mathrm{Ni}$ content over $3.6 \%$ promotes hypereutectic solidification manner including the further reactions $\left[\mathrm{L} \rightarrow \mathrm{Al}_{3} \mathrm{Ni}\right], \quad\left[\mathrm{L}+\mathrm{Al}_{3} \mathrm{Ni}+(\mathrm{Al})\right]$ and $\left[\mathrm{L}+\mathrm{Al}_{3} \mathrm{Ni}+(\mathrm{Al})+\mathrm{T}\right]$. When considering the $\mathrm{Al}-8 \% \mathrm{Zn}-7 \% \mathrm{Ni}-3 \% \mathrm{Mg}$ alloy, a fractions of primary and eutectic $\mathrm{Al}_{3} \mathrm{Ni}$ phase are nearly equal and their total amount composes 12.8 vol.\%. This phase is reliably indicated by elemental mapping and presented in SEM microstructure (fig.2) as bright constituents of spheroidal agglomerated and rod-like shapes surrounded by grey (Al) dendrites. In the vicinity, dark $\mathrm{T}$ phase veins are revealed appeared as a result of

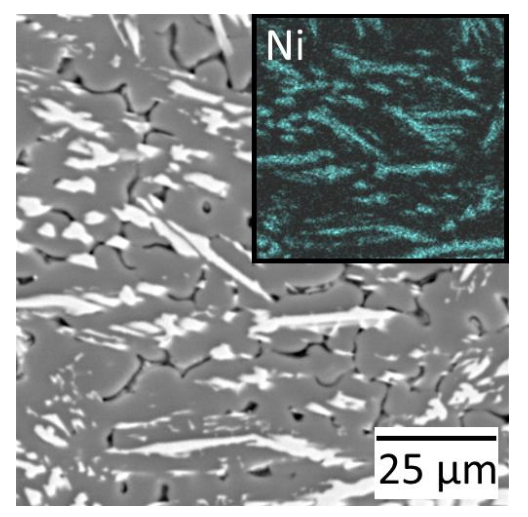

Fig. 2. As-cast microstructure of the $\mathrm{Al}-8 \% \mathrm{Zn}-7 \% \mathrm{Ni}-3 \% \mathrm{Mg}$ alloy (SEM) and elemental mapping focused on $\mathrm{Ni}$ spectre 
non-equilibrium solidification. Generally, the phases retained after solidification agree the calculation data.

According to Scheil-Gulliver curves (fig. 3), in Al$8 \% \mathrm{Zn}-7 \% \mathrm{Ni}-3 \% \mathrm{Mg}$ the $\mathrm{Al}_{3} \mathrm{Ni}$ primary phase occurs prior to $(\mathrm{Al})$ solid solution at the temperature of about $700{ }^{\circ} \mathrm{C}$. Then, after formation of (Al) dendritic network and $\mathrm{Al}_{3} \mathrm{Ni}$ eutectic-origin phase, the non-equilibrium solidification $\mathrm{T}$ phase appears at $478{ }^{\circ} \mathrm{C}$. The latter temperature is mainly constant and does not depend on Ni content. The results of the hot tearing test showed that HTS index (defined as the least diameter of a crack-free sample) for $\mathrm{Al}-8 \% \mathrm{Zn}-3 \% \mathrm{Mg}$ is $16 \mathrm{~mm}$ and addition of $\mathrm{Ni}$ contributes to improvement of hot tearing tendency down to $12 \mathrm{~mm}$ for $\mathrm{Al}-8 \% \mathrm{Zn}-7 \% \mathrm{Ni}-3 \% \mathrm{Mg}$ alloy. This improvement can be described by slightly dwindled effective solidification range (ESR). According to [26] the ESR value for Al-Zn-Mg-Ni alloys can be described using Scheil-Gulliver curves as a difference between the temperature at which $85 \%$ solid phases were formed (start of the linear shrinkage) and the non-equilibrium solidus. The ESR value descends with an increase in $\mathrm{Ni}$ content, but the change is negligible $\left(\sim 10{ }^{\circ} \mathrm{C}\right)$. The influence of $\mathrm{Ni}$ on the improvement of the HTS index of $\mathrm{Al}-\mathrm{Zn}-\mathrm{Mg}-\mathrm{Cu}$ alloys was described in [14]. The key aspect used was the Cracking Susceptibility Coefficient (CSC) developed by Clyne and Davies in [27]. Making the assumption that a time when a solid fraction is at 0.9 , 0.99 and 0.4 can be replaced by the temperature, the formula looks as follows:

$$
C S C=\frac{T_{0.9}-T_{0.99}}{T_{0.4}-T_{0.9}}
$$

Thus it can be seen that the CSC value is significantly reduced with addition of $\mathrm{Ni}$ (from 0.87 for $\mathrm{Al}-8 \% \mathrm{Zn}$ $3 \% \mathrm{Mg}$ to 0.62 for $\mathrm{Al}-8 \% \mathrm{Zn}-7 \% \mathrm{Ni}-3 \% \mathrm{Mg}$ ) even at hypereutectic concentrations.

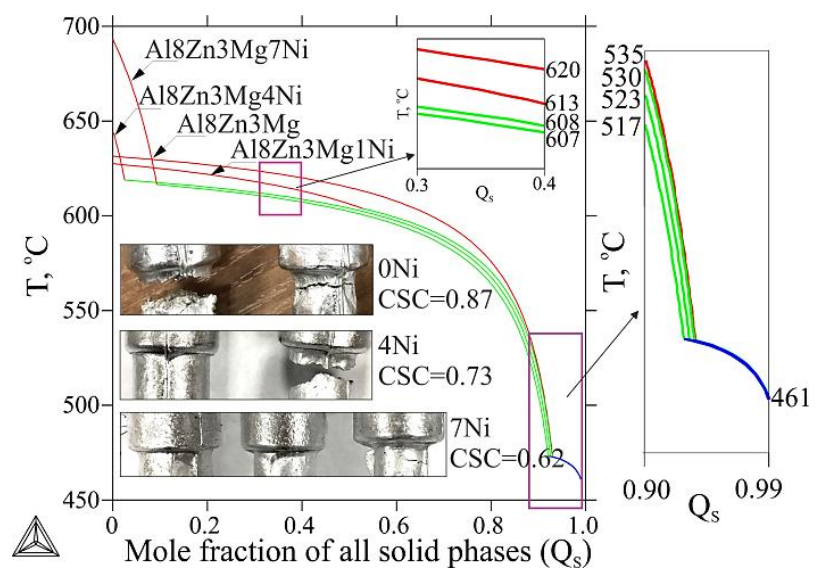

Fig. 3. Scheil-Gulliver curves and hot tearing susceptibility of the experimental alloys

Another factor contributed to the improvement of hot tearing resistance is an adequate amount of eutectic liquid promoting healing of incipient cracks during contraction at the latter stages of solidification. In our test the fewer diameters of sample the higher tensile stress is induced accompanied by an increase in amount of interdendritic channels appeared after rupture of liquid film. In that sense, whilst in the base alloy no eutectic melt can refill these channels, in case of Ni-rich alloy presence of the sufficient eutectic volume $\left.\left[(\mathrm{Al})+\mathrm{Al}_{3} \mathrm{Ni}\right)\right]$ shows an observable effect in the test samples of up to $12 \mathrm{~mm}$. It is believed that the achievement can be critical for producing quality L-PBF parts at industrial processing parameters.

\subsection{Characterization of powder batch}

The initial chips were enough brittle for easily milling within a low duration. A ubiquitous issue in HEBM processing is a contamination of the powder from the milling media. In our case the enhanced oxidation may occur and iron may be captured from a grinding bowl and balls. However, we assume that the milling time is relatively low and these factors may be ignored.

On the other hand it is obvious that the quality of powder has a crucial impact on the defects appearing in the L-PBF parts. It is rather necessary to use spherical powder produced by atomization methods. However, we consider these methods as very expensive ones. In order to preliminary estimate the processability of the experimental alloys by L-PBF, we decided to try out to use milled powder. Thus, the flowability is not supposed to be the key parameter in the present study.

Figure 4 represents a particle-size distribution of the powder from the experimental $\mathrm{Al}-8 \% \mathrm{Zn}-7 \% \mathrm{Ni}-3 \% \mathrm{Mg}$ alloy. It can be seen that some occasional particles exceeding $100 \mu \mathrm{m}$ in size are observed and therefore the experiment promises to be slightly tough. In this case we chose a bit lower scanning speed to provide appropriate melting and fusion of the particles. Nevertheless, the experimental powder has a SPAN parameter of 1.1 which can provide an excellent flowability. Thus, the usage of such powder can be promising in assessment of new alloys for L-PBF.

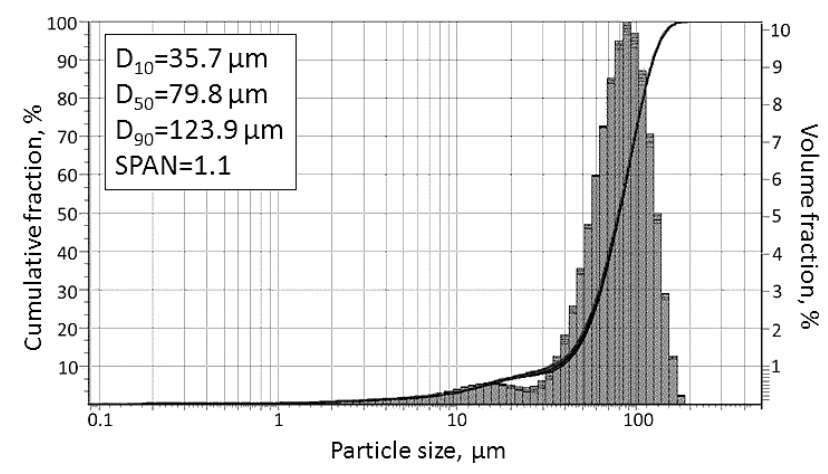

Fig. 4. Particle-size distribution of the experimental powder

The powder consisted of irregular and coarse particles with rough surfaces (fig. 5a). Each coarse plate of $\mathrm{Al}_{3} \mathrm{Ni}$ phase, presented in the as-cast state, was split into fine unevenly distributed particles (fig. 5b). This structure looks like a composite in which the particles play a reinforcing role for aluminum-based matrix. 


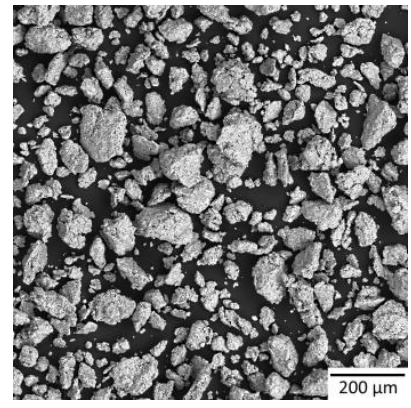

a

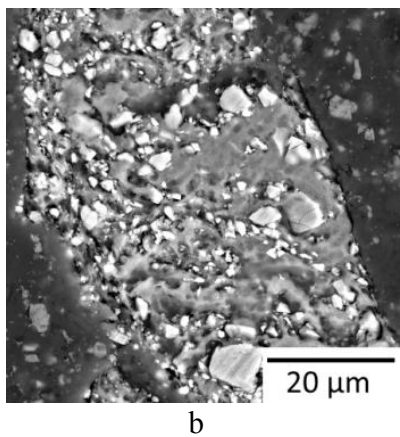

b

Fig. 5. Shape of the powder particles (a) and the structure the individual particle (b)

Since the SLM 280 HL industrial machine has its own filter and hopper system (without transfer powder from one to another platform) which require for smooth and spherical powder, we were forced to place the powder manually with its sequent levelling by carriage.

\subsection{Single track scanning experiment}

Twelve single tracks were studied by OM and SEM methods. From on-top IMAGES made at the $5 \mathrm{~mm}$ distance from the start of laser travelling, it is clearly seen that all tracks have defects such as irregularity and balling (fig. 6a). It is likely that the prolonged light surface is caused by sufficient fusion and consolidation of the melt pool. Since conditions applied are greatly far from common ones (e.g. scanning speed is about 4 times less than that ones for branded Al10SiMg alloy), we suppose that the laser melting of the ball milled powder was accompanied with a significant wetting of the substrate (fig. 6b), associated with low scanning speed.
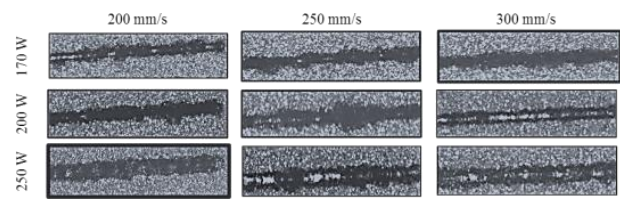

a

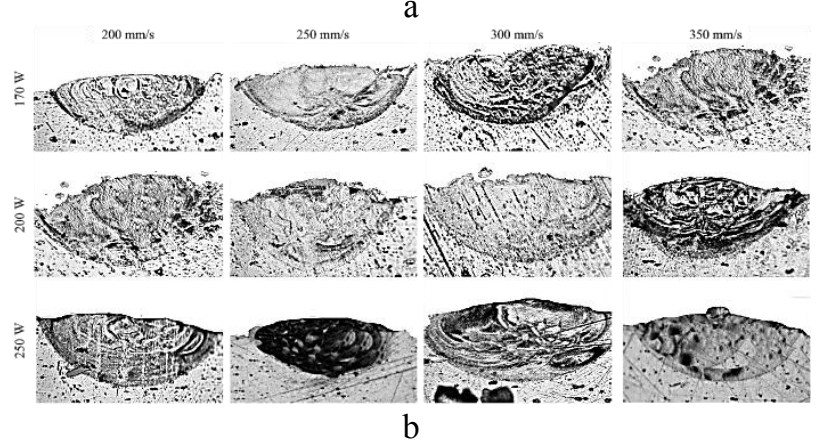

Fig. 6. On-top view (a) and cross-section images (b) of the single tracks

Analysis of the cross-section images (fig. 7) showed that the width of the molten pool increases with an increase in laser power from $140 \mu \mathrm{m}$ (for $170 \mathrm{~W}$ ) to $220 \mu \mathrm{m}$ (for $250 \mathrm{~W}$ ). Relatively deep penetration of about 50-100 $\mu \mathrm{m}$ was observed for all samples. It is complicated to reveal any associations between processing parameters and molten pool geometry due to a high degree of randomness. For example, the track obtained at $250 \mathrm{~W}$ and $350 \mathrm{~mm} / \mathrm{s}$ has a width of $330 \mu \mathrm{m}$ (appeared to be the largest one), that is not reasonable because it must have become slender due to an increase in the scanning speed.

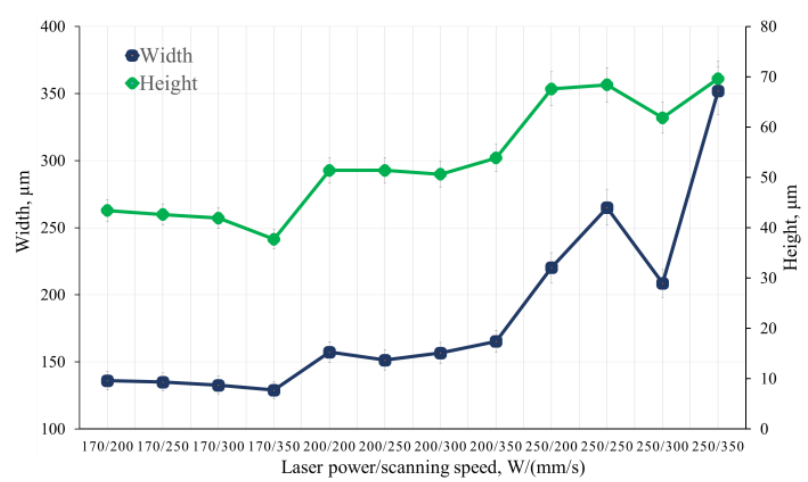

Fig. 7. Width and height measured on the cross-sections of the single tracks

Nevertheless, there is a great difference among the structures of the tracks and some regularity has been found. The traits of the cross-section structures are the evidential inhomogeneity caused by turbulence and Marangoni flow occurred after laser power irradiation. Temperature gradients generated coupled heat- and mass-transfer processes and that's why the concentration fluctuation is well visible in optical images as dark coloured vortexes. They are most likely indicating the level of interaction between the Al-8\% $\mathrm{Zn}-7 \% \mathrm{Ni}-3 \% \mathrm{Mg}$ alloy powder and the 5052 grade alloy substrate.

We chose the most representative types of structures appeared in individual tracks fabricated at $250 \mathrm{~W}$ and studied them by SEM. The track obtained at $250 \mathrm{~W}$ and $200 \mathrm{~mm} / \mathrm{s}$ has a structure (fig. 8a) in which the amount of the experimental alloy decreased approximately fivefold due to lower scanning speed and intense mixing with substrate. Some cracks and porosity are also observed. The most successful track was built at $250 \mathrm{~W}$ and $250 \mathrm{~mm} / \mathrm{s}$. The $\mathrm{OM}$ revealed that it has the darkest surface and from the SEM structure (fig.8b) it is clear that the experimental alloy-rich area (designated as $\mathrm{Ni}$ rich area) is concentrated on the right sight of the track. In comparison to the previous track, there is more than $4 \% \mathrm{Ni}$, but just about $2 \% \mathrm{Zn}$ that is probably due to some evaporation. The left side map shows the Substrate/alloy mixing about $5 / 1$ likewise as in the previous track. The widest track fabricated at $250 \mathrm{~W}$ and $350 \mathrm{~W}$ has a structure without dark vortexes. Only some segregated parts of the cross-sections are indicated to be the experimental alloy (fig. 8c). It is interesting that the displaced region revealed at the up-left side is enough convex and slightly penetrated into the substrate that confirm its remelting during laser travelling. Ultimately, the structure of the Ni-rich area is much finer than in the powder sample, so that it is believed to have a pseudoeutectic structure. 

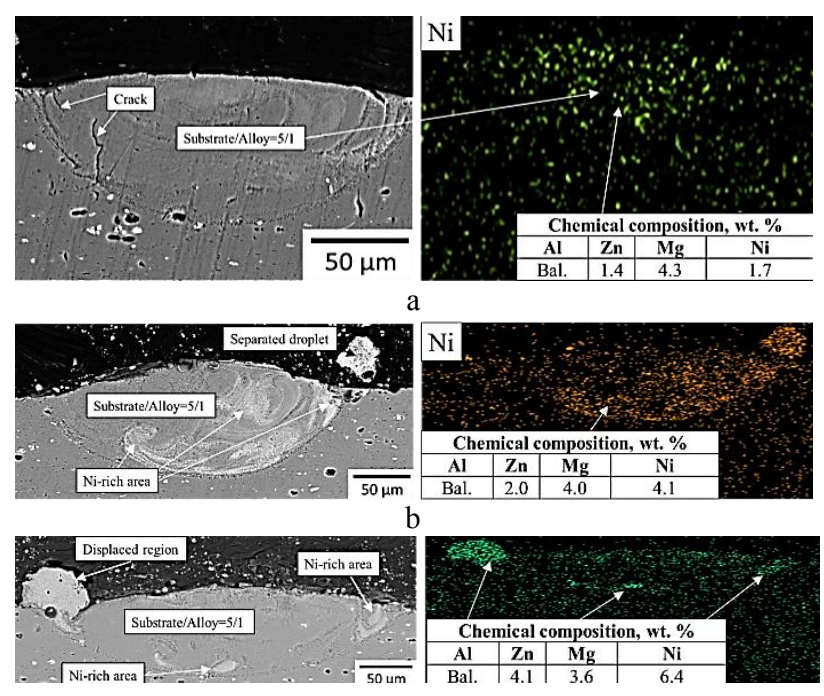

Fig. 8. Cross-section microstructures of the single tracks, fabricated at a laser power and a scanning speed: $\mathrm{a}-250 \mathrm{~W}$ and $200 \mathrm{~mm} / \mathrm{s} ; \mathrm{b}-250 \mathrm{~W}$ and $250 \mathrm{~mm} / \mathrm{s} ; \mathrm{c}-250 \mathrm{~W}$ and $350 \mathrm{~mm} / \mathrm{s}$

\section{Conclusions}

In summary, whilst the experiment was relatively tough for arguing that the new $\mathrm{Al}-8 \% \mathrm{Zn}-7 \% \mathrm{Ni}-3 \% \mathrm{Mg}$ alloy is excellent for L-PBF, some important conclusions for further research were drawn:

1) $\mathrm{The} \mathrm{Al}-8 \% \mathrm{Zn}-7 \% \mathrm{Ni}-3 \% \mathrm{Mg}$ has an advantageous hot tearing resistance due to lower effective solidification range and adequate amount of $\left[(\mathrm{Al})+\mathrm{Al}_{3} \mathrm{Ni}\right]$ eutectic in comparison to the base $\mathrm{Al}-8 \% \mathrm{Zn}-3 \% \mathrm{Mg}$ alloy and neareutectic $\mathrm{Al}-8 \% \mathrm{Zn}-4 \% \mathrm{Ni}-3 \% \mathrm{Mg}$ alloy.

2) The feedstock powder material of $100 \mu \mathrm{m}$ size for L-PBF was prepared via machining of initial cast ingot into chips and further HEBM. The SPAN and $\mathrm{D}_{50}$ values were 1.1 and $79.8 \mu \mathrm{m}$ respectively. While the powder had mostly irregular shape, the structure contained grinded fine unevenly distributed $\mathrm{Al}_{3} \mathrm{Ni}$ intermetallics.

3) A comparative evaluation of the twelve single tracks fabricated at a laser power of 170-250 W and scanning speed of $200-350 \mathrm{~mm} / \mathrm{s}$ was carried out. The low quality of powder likely caused the irregularity of tracks. Moreover, it was shown that a relatively low scanning speed leaded to significant wetting of the substrate and turbulence. The latter represented as vortexes and mixing between the experimental alloy and the substrate.

4) Three types of the single tracks fabricated at $250 \mathrm{~W}$ and different scanning speed were studied in detail. The structure of the first track fabricated at $200 \mathrm{~mm} / \mathrm{s}$ showed cracks and porosity as well as a substrate/alloy mixing of $5 / 1$. Increase of scanning speed up to $250 \mathrm{~mm} / \mathrm{s}$ promoted the least level of mixing in the second track. It contained no porosity and cracks, but some amount of zinc was evaporated. The third track fabricated at 350 $\mathrm{mm} / \mathrm{s}$ showed a random displaced region, which contained more than $6 \% \mathrm{Ni}$ indicating on the initial alloy. It has an ultrafine structure provided by rapid solidification.

5) Further research will follow the path toward softening of the experimental conditions. The key approach will be focused on more sufficient grinding of the powder and on trying out higher laser velocity and its power. It is believed that the proposed feedstock is promising for assessment of the new alloys for L-PBF.

This research was funded by the Russian Science Foundation (project no. 19-79-30025)

\section{References}

1. T.S. Srivatsan, T.S. Sudarshan, Additive Manufacturing Innovations. Advances and Applications (CRC PRESS. Taylor \& Francis Group, 2015)

2. R. Deb, T. Wei, H.L. Zuback, J.S. Mukherjee, T. Elmer, J.W. Milewski, J.O. Beese, A.M. WilsonHeid, A. De, W. Zhang, Progress in Materials Science, 92, 112-224 (2018)

3. D. Herzog, V. Seyda, E. Wycisk, C. Emmelmann, Acta Mater. 117, 371-392 (2016)

4. C. Galy, E. Le Guen; E. Lacoste; C. Arvieu, Add. Manuf. 22, 165-175 (2018)

5. M. Glazoff, A. Khvan; V. Zolotorevsky, N. Belov; A. Dinsdale, Casting Aluminum Alloys. 2nd Edition: Their Physical and Mechanical Metallurgy (Elsevier, 2018)

6. J. Liu, Z. Liu, Y. Jiang, G.W. Wang, Y. Yang, L.C. Zhang, JALCOM, 735, 1414-1421 (2018)

7. W. Pei, W. Zhengying, C. Zhen; D. Jun, H. Yuyang, L. Junfeng, Z. Yatong, Appl. Surf. Sci. 408, 38-50 (2017)

8. N. Read, W. Wang, K. Essa, M. Attallah Moataz, Mater. Des. 65, 417-424 (2015)

9. P. Wang, H.C. Li, K.G. Prashanth, J. Echert, S. Scudino, JALCOM, 707, 287-290 (2017)

10. R. Casati, M. Coduri, M. Riccio, A. Rizzi, M. Vedani, JALCOM, 801, 243-253 (2019)

11. M.L. Montere-Sistiaga, R. Mertnens, B. Vrancken, X. Wang, B. van Hooreweder, J.-P. Kruth, J. van Humbeeck, J. Mater. Process. Technol. 238, 437-445 (2016)

12. N.A. Belov. Russian Journal of Non-Ferrous Metals, 3, 243-249 (2010)

13. N.A. Belov, A.V. Khvan, A.N. Alabin, Mater. Sci. Forum, 519-521, 395-400 (2006)

14. F. Liu, X. Zhu, S. Ji, JALCOM, 821, 153458 (2020)

15. P. Ma; K.G. Prashanth; S. Scudino, Y. Jia, H. Wang, C. Zou, Z. Wei, J. Eckert, Metals, 4, 28-36 (2014)

16. J. Zhang, B. Song, Q. Wei, D. Bourell, Y. Shi, J. Mater. Process. Technol. 35, 270-284 (2019)

17. K.T. Kim, J.H. Yang, Y.S. Lim, J. Kor. Foundry Soc. 32, 38-43 (2012)

18. J.E. Hatch, Aluminum: Properties and Physical Metallurgy (American Society for Metals, 1984)

19. R. S. Barclay, H. W. Kerr, P. Niessen, Journal of Materials Science, 6, 1168-1173 (1971) 
20. G. Gonzalez, G.A. Lara-Rodriguez, A. SandovalJiménez, W. Saikaly, A. Charai, Materials Characterization, 59, 1607-1612 (2008)

21. B. Fullenwider, P. Kiani, J. M. Schoenung, K. Ma, Powder Technology, 342, 562-571 (2019)

22. Q. Han, R. Setchi, S. L. Evans, Powder Technology, 297, 183-192 (2016)

23. Thermo-Calc Software TTAL5 Al-Alloys. URL: www.thermocalc.com (access date: 17.01.2020)

24. R. Baitimerov, P. Lykov, D. Zherebtsov, L. Shultc, A. Radionova, K.G. Prashanth, Materials, 11, 742 (2018)

25. P. Shurkin, T. Akopyan, N.Korotkova, A. Prosviryakov, A. Bazlov, A. Komissarov, D. Moskovskikh, Metals, 10, 762 (2020)

26. V. S. Zolotorevskii, A. V. Pozdnyakov, A. Yu. Churyumov, The Physics of Metals and Metallography, 115, 286-294 (2014)

27. T.W. Clyne, G.J. Davies, Br. Foundryman, 74, 65-73 (1981) 